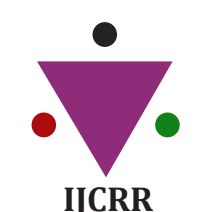

IJCRR

Section: Healthcare

ISI Impact Factor

(2019-20): 1.628

IC Value (2019): 90.81

$\operatorname{SJIF}(2020)=7.893$

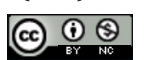

Copyright@IJCRR

\title{
An In Vitro Assessment of Retention Force for Implant-Retained Overdentures Using All-Polyetheretherketone, Zirconia, and Titanium Attachments
}

\author{
Mahalakshmi Gujjalapudi', Amit Kumar Verma², Swaroopkumar M Magar ${ }^{3 *}$, \\ Doddy Lokanathan Balaji ${ }^{4}$, Gagandeep Singh Dang ${ }^{5}$, Atul Bhardwaj ${ }^{6}$
}

\begin{abstract}
'Associate Professor, Department of Prosthodontics, Government Dental College, Kadapa, Andhra Pradesh, India; 'Department of Prosthodontics, ECHS Polyclinic, Hardoi, India; ${ }^{3}$ Reader, Department of Prosthodontics, Saraswati Dhanwantari Dental College and Research Institute, Perbhani, Maharastra, India; 4 Senior Lecturer, Department of Prosthodontics, Priyadrshini Dental College and Hospital, Thiruvallur, 631203, India; 5Private Practitioner, Dr Dang's Multispeciality Dental Clinic and Implant Centre, Lajpat Nagar part-1, New Dehli, India; ${ }^{6}$ Department of Prosthodontics, College of Dentistry, Majmaah University, Al Majmaah -11952, Saudi Arabia.
\end{abstract}

\section{ABSTRACT}

Introduction: Numerous problems were described by complete denture wearers for example lack retention and stability of these dentures, thus decreasing chewing efficacy, and pain during mastication. These problems can be effectively overwhelmed with implant-assisted overdentures.

Objectives: This study was done to assess the retention forces of all-zirconia $\left(\mathrm{ZrO}_{2}\right)$, all-polyetheretherketone (PEEK), and titanium for two implant-retained mandibular overdentures.

Materials and Methods: In each model, twenty-four similar acrylic resin mode positioned at the canine area. Models were categorized into 4 groups of 7 samples in each group; all all-zirconia $\left(\mathrm{ZrO}_{2}\right)$, all-polyetheretherketone $(\mathrm{PEEK})$, titanium and a combination of PEEK with zirconia. Alike experimental overdentures were prepared for all models. A universal testing machine was used for assessing the retention force, using the pull-off test in the existence of artificial saliva in-between the crowns. A higher score of retention force was noted at the beginning and after 540 cycles of insertion and elimination which mimicking 6 months of the clinical outcome of final retention. Obtained results were statistically evaluated.

Results: Zirconia group conveyed the greatest initial force values. A combination of zirconia and PEEK was found to be effective. The final retention values of the PEEK and Zirconia groups were significantly decreased than initial values, while the insignificant loss of retention was observed with the Titanium group $(P=0.05)$.

Conclusion: Zirconia $\left(\mathrm{ZrO}_{2}\right)$ with PEEK combination is more preferred as a secondary telescopic. Despite the retention loss with time, even PEEK can be recommended as a secondary telescopic crown beside PEEK or $\mathrm{ZrO}_{2}$ primary crowns concerning the adequate early and final retention scores.

Key Words: PEEK, Retention force, Telescopic attachment, Zirconia

\section{INTRODUCTION}

Numerous problems were described by complete denture wearers for example lack retention and stability of these dentures, thus decreasing chewing efficacy, and pain during mastication. These problems can be effectively overwhelmed with implant-assisted overdentures. ${ }^{1}$

Resilient telescopic supplements have been used since 1989, to retain overdentures for rehabilitation of the edentulous mandible. In cases of overdenture for long term success, two interforaminal implants with resilient telescopic attachments appeared to be an effective and efficient treatment option in cases of the severely atrophied edentulous mandible. ${ }^{2}$

In 2000 using ceramic materials for the fabrication of telescopic attachments was first defined. Zirconia $\left(\mathrm{ZrO}_{2}\right)$ is a ceramic material that is largely used in current years for medical devices, displaying excellent mechanical strength, high biocompatibility, and wear resistance. The use of tooth-

\section{Corresponding Author:}

Dr. Swaroopkumar M Magar, Reader, Department of Prosthodontics, Saraswati Dhanwantari Dental College and Research Institute, Perbhani, Maharastra, India; E-mail: drmagar@rediffmail.com

ISSN: 2231-2196 (Print)

Received: 23.07 .2020
ISSN: 0975-5241 (Online)

Revised: 12.10 .2020
Accepted: 12.06 .2021
Published: 20.07 .2021 
coloured ceramic materials display a positive psychological outcome on patients and upholds improvements in oral hygiene. $^{3}$

Polyetheretherketone (PEEK) is a thermoplastic polymer, comprise of a molecular chain from an aromatic backbone that is connected by ketone and ether function group. ${ }^{4}$ PEEK exhibits high biocompatibility and can be used for numerous dental conditions, such as dental implants, and provisional abutments. ${ }^{5,6}$

The present study was done to evaluate the retention force of different CAD/CAM telescopic attachments (zirconia, PEEK, and titanium telescopic attachments) for retention of mandibular implant overdenture.

\section{MATERIALS AND METHOD}

In the present study twenty-one, acrylic resin models of edentulous mandible without alveolar undercuts were used. Every model was surrounded by a $2 \mathrm{~mm}$ layer of silicon soft liner material to mimic alveolar mucosa in accordance to El-Charkawi et al. ${ }^{7}$ Two implants with $10 \mathrm{~mm}$ length and $4.5 \mathrm{~mm}$ diameter (dentium implants) were mounted in the canine area of the respective model with the help of a template guide, ${ }^{8}$ later two dual abutments with 4.5 diameters, 1.5 gingival height and 4.5 lengths, were positioned into the implants. For overdenture construction, the resin models were duplicated. Models were divided into 4 groups; group zirconia, PEEK, titanium and PEEK+ zirconia materials.

\section{Fabrication and designing and of telescopic attachments}

Primary resilient telescopic crown construction was done with the succeeding parameters for all groups; $5 \mathrm{~mm}$ height ( $2 \mathrm{~mm}$ gingival height was paralleled and the occlusal $3 \mathrm{~mm}$ was tapered $4^{\circ}$ ). The primary crowns were intended to ensure a shared path of insertion. The computer numeric control data were preserved as STL files. From semi-sintered $\mathrm{ZrO}_{2}$ blanks $\left(\mathrm{ZrO}_{2}\right.$, Kataya) the primary $\mathrm{ZrO}_{2}$ crowns were milled and from BioHPP blanks (Bredent, UK) the primary PEEK crowns were milled. Using zinc phosphate cement on an abutment the primary crowns were cemented.

Secondary resilient telescopic crown construction was done by scanning each model, followed by separate scans of each primary crown to improve the quality of data. The subsequent parameters were employed for designing secondary crowns; parallel walls with a minimal wall thickness of 0.5 $\mathrm{mm}$ and occlusal space $(0.3 \mathrm{~mm})$ built-in between the primary and secondary crowns. ${ }^{2}$ Mechanical projections were added to the design of each secondary crown, and later secondary $\mathrm{ZrO}_{2}$ and PEEK crowns were adopted.

\section{Secondary crown procedures}

The fitting area was altered by creating vent holes through the lingual flanges of each overdenture. Secondary crowns were built-in over the primary ones in the correct path of insertion and then picked up to the fitting surface of the overdenture using an auto polymerized acrylic resin.

\section{Measurement of retention force}

With auto polymerized acrylic resin a metallic cobalt chrome bar $(2 \mathrm{~mm}, 15 \mathrm{~mm}$, and $120 \mathrm{~mm})$, with a grasping hook in the middle, was covered. ${ }^{9}$ For measuring the retention force, models were placed and fixed in a universal testing machine (LLOYD instruments) then a pull-off test was performed with a load cell of $3.5 \mathrm{KN}$ and a crosshead speed of $50 \mathrm{~mm} /$ min. Overdenture with each combination of secondary and primary telescopic crowns was exposed to 540 cycles of enclosure and exclusion representing 6 months of clinical service under the same circumstances. Then, the pull-off test was achieved again to assess the final retention.

The obtained data were tabulated and statistically evaluated using the SPSS version 21(SPSS Inc., Chicago, Illinois, USA) using Shapiro-Wilk test, Independent samples test, ANOVA was used followed by the post hoc Tukey test. $P$ value was lesser than 0.05 measured as statistically significant.

\section{RESULTS}

Table 1 indicated, the average values of initial and final retention values (telescopic attachment) in all groups. The highest mean initial retention value for all groups was observed in Group-I where the mean initial retentive force was $21.2550 \mathrm{~N}$ and the final one was $16.1140 \mathrm{~N}$. However, mean initial retentive forces of group 2 (Titanium) and 3 (PEEK) $14.6310 \mathrm{~N}$ and $15.3530 \mathrm{~N}$ respectively and their final retentive forces were $14.4160 \mathrm{~N}$ and $14.0470 \mathrm{~N}$ respectively. Group IV for the combination of Zirconia+ PEEK showed initial forces as $17.3430 \mathrm{~N}$ and $16.0340 \mathrm{~N}$ final forces.

Comparison of mean values between initial and final retention values within each group using paired $t$-test showed that the final retention value for the PEEK and Zirconia and $\mathrm{Zr}+\mathrm{PEEK}$ was significantly decreased by time $(P=0.0001$, 0.0000 and 0.0001 ) respectively), but no significant loss in retention force value was observed for the titanium group where $P=0.057$.

Table 2 indicated the Initial and final retention values comparison among all groups. There was a significant variance in both initial and final retentions between every two groups using the Independent samples test. 


\section{DISCUSSION}

For achieving clinical performance and patient satisfaction of the prosthesis, it is necessary to maintain retention of the attachment system. 3

In the present study, the highest mean initial retention values were found in the Zirconia group followed by PEEK. Our results are in agreement with the in vitro study of Schubert et al. ${ }^{10}$ they observed that CAD-CAM fabricated PEEK secondary crowns can deliver sufficient retention force values.

Final retention values of PEEK and Titanium groups were significantly decreased than initial values, while insignificant loss of retention was observed with the zirconia group; this may be owing to wear and alteration in surface topography of the secondary and primary crowns opposing areas. It was described that, during the function of telescopic attachment, frictional wear can occur. ${ }^{11,12}$

Emera et al., assessed the changes in surface topography of all $\mathrm{ZrO}_{2}, \mathrm{ZrO}_{2}$-PEEK and all PEEK, telescopic attachments after simulated 6 months of using the overdenture. ${ }^{13}$ They determined that the PEEK and $\mathrm{ZrO}_{2}$ combination for the fabrication of telescopic attachment was attended with superior variations in surface topography (mostly in secondary crowns) in association with all PEEK and all $\mathrm{ZrO}_{2}$ telescopic connections..$^{14,15}$

A significant change among the initial and final retention between all groups was observed due to significant wear that occurred in all groups after simulating 6 months of overdenture. $^{16}$

\section{CONCLUSION}

It can be concluded that $\mathrm{ZrO}_{2}$ is further desired as a secondary telescopic crown. Although the loss of retention over time, PEEK can still be used as a secondary telescopic crown against titanium or PPEK primary crowns regarding the acceptable initial and final retention values.

Conflict of interest: nil

Source of funding: self

Authors contribution

1. Dr. Gujjalapudi M- Editing

2. Dr. Amit Verma- Manuscript writing

3. Dr. Swaroopkumar M Magar- Data collection, investigation

4. Dr. Balaji- Review

5. Dr. Gagandeep Singh Dang- Review

6. Dr. Atul Bhardwaj- Editing

\section{REFERENCES}

1. Chen YF, Yang YH, Lee JH, Chen JH, Lee HE, Chou TM. Tongue support of complete dentures in the elderly. Kaohsiung J Med Sci. 2012;28:273-278.

2. Heckmann SM, Schrott A, Graef F, Wichmann MG, Weber HP. Mandibular two-implant telescopic overdentures. Clin Oral Implants Res. 2004;15:560-569.

3. Weigl P, Hahn L, Lauer HC. Advanced biomaterials used for a new telescopic retainer for removable dentures. J Biomed Mater Res. 2000;53:320-336.

4. Kurtz SM, Devine JN. PEEK biomaterials in trauma, orthopaedic, and spinal implants. Biomater. 2007;28:4845-4869.

5. Merk S, Wagner C, Stock V, Eichberger M, Schmidlin PR, et al. Suitability of secondary PEEK telescopic crowns on zirconia primary crowns: The influence of fabrication method and taper. Materials. 2016;9:908-917.

6. Stock V, Wagner C, Merk S, Roos M, Schmidlin PR, et al. Retention force of differently fabricated telescopic PEEK crowns with different tapers. Dent Mater J. 2016;35:594-600.

7. El-Charkawi H, Zekry K, Elwaked M. Stress analysis of different osseointegrated implants supporting distal extension prosthesis. J Prosthet Dent. 1994;72: 1-5.

8. Ebadian B, Talebi S, Khodaeian N, Farzin M. Stress analysis of mandibular implant-retained overdenture with independent attachment system: Effect of restoration space and attachment height. Gen Dent. 2015;63:61-67.

9. El Mekawy N, Khalifa A, Abdualgabbar E. The influence of palatal coverage on the retention force and fatigue resistance of mini dental implant maxillary overdenture. J Oral Hyg Health. 2016;4:200-208.

10. Schubert O, Reitmaier J, Schweiger J, Erdelt K, Güth JF. The retentive force of PEEK secondary crowns on zirconia primary crowns over time. Clin Oral Investig. 2019;23:2331-2338.

11. Bayer S, Kraus D, Keilig L, Gölz L, Stark H, Enkling N. Wear of double crown systems: Electroplated vs. casted female part. J Appl Oral Sci. 2012;20:384-391.

12. Majcher A, Leśniewska-Kochanek A, Mierzwińska-Nastalska E. A method and a device for the evaluation of the retention of telescopic dental crowns. J Mech Behav Biomed Mater. 2017;69:362-367.

13. Emera R, Elgamal M, Albadwei M. Surface wear of all zicronia, all PEEK and zirconia-peek telescopic attachments for two implants retained mandibular complete overdentures. In -vitro study using the scanning electron microscope. IOSR J Dent Med Sci. 2019;18:59-68.

14. Turp I, Bozdağ E, Sünbüloğlu E, Kahruman C, Yusufoğlu I, Bayraktar G. Retention and surface changes of zirconia primary crowns with secondary crowns of different materials. Clin Oral Investig. 2014;18:2023-2035.

15. Rutkunas V, Mizutani H, Takahashi H. Influence of attachment wear on retention of mandibular overdenture. J Oral Rehabil. 2007;34:41-51.

16. Lughi V, Sergo V. Low-temperature degradation - ageing - of zirconia: A critical review of the relevant aspects in dentistry. Dent Mater. 2010;26:807-820. 
Table 1: Initial and final retention values comparison for telescopic attachment for group I

\begin{tabular}{lccc} 
Type & Initial & Final & P \\
Group-I (Zirconia) & $21.2550 \pm 1.52565$ & $16.1140 \pm 1.39403$ & $0.000^{*}$ \\
Group-II (Titanium) & $14.6310 \pm 1.04374$ & $14.4160 \pm 1.01853$ & 0.054 \\
Group-III (PEEK) & $15.3530 \pm 0.76212$ & $14.0470 \pm 0.75644$ & $0^{*}$ \\
Group IV (Zirconia +PEEK) & $17.3430 \pm 0.69211$ & $16.0340 \pm 0.28642$ & $0^{*}$ \\
\hline
\end{tabular}

*Significance<0.05, Test used: Student's $t$-test, SD=Standard deviation, P=Probability

Table 2: Table 2: Initial and final retention values comparison among all groups

\begin{tabular}{|c|c|c|c|c|c|c|c|}
\hline Retention type & Group I & Group II & Group III & Group IV & $\mathbf{P}_{1}$ & $\mathbf{P}_{2}$ & $\mathbf{P}_{3}$ \\
\hline Initial retention & $23.26 \pm 1.47$ & $16.53 \pm 1.0235$ & $17 \cdot 54 \pm 0.757$ & $17.3430 \pm 0.69211$ & $0.001^{*}$ & $0.001^{*}$ & $0.011^{*}$ \\
\hline Final retention & $18.12 \pm 1.45$ & $15 \cdot 35 \pm 0.0847$ & $16.07 \pm 0.36$ & $16.0340 \pm 0.28642$ & $0.001^{*}$ & $0.001^{*}$ & $0.033^{*}$ \\
\hline
\end{tabular}

*Significance $<0.05$. Test used=Independent samples test, $\mathrm{P}_{1}=$ Significance between Group I and Group II, $\mathrm{P}_{2}=$ Significance between Group I and

Group III, $\mathrm{P}_{3}=$ Significance between Group II and Group III, P=Probability, SD=Standard deviation 